\title{
Ultrasound-Guided Regional Anesthesia-Current Strategies for Enhanced Recovery after Cardiac Surgery
}

\author{
Cosmin Balan ${ }^{1, *(\mathbb{D}}$, Serban-Ion Bubenek-Turconi ${ }^{1,2}$, Dana Rodica Tomescu ${ }^{2,3}$ (i) and Liana Valeanu ${ }^{1,2}$ \\ 1 1st Department of Cardiovascular Anesthesiology and Intensive Care, "Prof. C. C. Iliescu” Emergency \\ Institute for Cardiovascular Diseases, 258 Fundeni Road, 022328 Bucharest, Romania; \\ bubenek@alsys.ro (S.-I.B.-T.); liana.valeanu@yahoo.com (L.V.) \\ 2 Department of Anesthesiology and Intensive Care, University of Medicine and Pharmacy "Carol Davila", \\ 8 Eroii Sanitari Blvd, 050474 Bucharest, Romania \\ 3 3rd Department of Anesthesiology and Intensive Care, Fundeni Clinical Institute, 258 Fundeni Road, \\ 022328 Bucharest, Romania; danatomescu@gmail.com \\ * Correspondence: cosmin13mara@yahoo.com; Tel.: +40-722751501
}

Citation: Balan, C.; Bubenek-Turconi, S.-I.; Tomescu, D.R.; Valeanu, L. Ultrasound-Guided Regional Anesthesia-Current Strategies for Enhanced Recovery after Cardiac Surgery. Medicina 2021, 57, 312. https: / / doi.org/10.3390/ medicina57040312

Received: 11 February 2021

Accepted: 22 March 2021

Published: 25 March 2021

Publisher's Note: MDPI stays neutral with regard to jurisdictional claims in published maps and institutional affiliations.

Copyright: (c) 2021 by the authors. Licensee MDPI, Basel, Switzerland. This article is an open access article distributed under the terms and conditions of the Creative Commons Attribution (CC BY) license (https:// creativecommons.org/licenses/by/ $4.0 /)$.

\begin{abstract}
With the advent of fast-track pathways after cardiac surgery, there has been a renewed interest in regional anesthesia due to its opioid-sparing effect. This paradigm shift, looking to improve resource allocation efficiency and hasten postoperative extubation and mobilization, has been pursued by nearly every specialty area in surgery. Safety concerns regarding the use of classical neuraxial techniques in anticoagulated patients have tempered the application of regional anesthesia in cardiac surgery. Recently described ultrasound-guided thoracic wall blocks have emerged as valuable alternatives to epidurals and landmark-driven paravertebral and intercostal blocks. These novel procedures enable safe, effective, opioid-free pain control. Although experience within this field is still at an early stage, available evidence indicates that their use is poised to grow and may become integral to enhanced recovery pathways for cardiac surgery patients.
\end{abstract}

Keywords: cardiac surgery; enhanced recovery; regional anesthesia; ultrasound; paravertebral blocks; fascial plane blocks; nociception level index

\section{Introduction}

Cardiac surgery (CS) generates a unique set of challenges compared to non-cardiac surgery. Postoperative outcomes and quality of life result from several factors, including demographic characteristics, comorbidities, type and quality of surgical intervention, the extent of the systemic inflammatory response, range of organ dysfunction and pain [1-4]. Conveniently, many of these factors are amenable to optimization. To this end, enhanced recovery after surgery (ERAS) programs have evolved and are now commanded by a multidisciplinary consensus in CS [5].

Pain management is a crucial element of cardiac ERAS. Adequate analgesia is a prerequisite to ensure patient comfort, low morbidity, early mobilization, and cost effectiveness. Postoperative pain is multifaceted and may result from various interventions, including sternotomy, thoracotomy, chest drains and leg vein harvesting. One study found that maximal pain intensity in CS was usually moderate [6], but severe acute postoperative pain was also reported elsewhere and more frequently associated with chronic post-sternotomy pain [7].

Traditionally, opioids were considered the mainstay for pain management after CS based on a predictable hemodynamic profile. Acknowledged risks associated with their use (e.g., hyperalgesia, opioid dependence, respiratory depression, nausea and vomiting, immunosuppression, ileus, delirium, prolonged postoperative recovery) fueled that which now represents a central tenet in the ERAS paradigm-multimodal analgesia (MA) [8]. MA built on drug combinations is not faultless [9]; N-methyl-D-aspartate (NMDA) antagonists 
may bring about sympathetic hyperactivity, central alpha-2 agonists can cause bradycardia and hypotension, and nonsteroidal anti-inflammatory agents are associated with renal dysfunction and abnormal clotting.

Regional anesthesia/analgesia (RA) represents a valid alternative for the MA repertoire. It obviates many of the drawbacks of drug-based MA strategies, albeit with its particular challenges [10]. Classical neuraxial techniques such as thoracic epidural anesthesia (TEA) and landmark-based paravertebral blocks (PVB $\left.\mathrm{LM}_{\mathrm{L}}\right)$ constituted the standard regional approach to ensure chest wall pain relief before ultrasound (US) virtually revolutionized RA. Bleeding complications (e.g., spinal epidural hematoma (SEH)) were the primary concern regarding the use of TEA and PVB $\mathrm{LM}_{\text {in }}$ CS [11]. This may explain to some extent why CS fell behind other surgical specialties regarding the large-scale implementation of ERAS programs. Since its inception, US-guided RA (USRA) has helped improve existing techniques (i.e., PVB) and favored the design of new ones. Specifically, real-time US needle-tracking is essential to perform chest wall fascial plane blocks (CWFPB) [12]. Delivery of local anesthetics (LA) between myofascial layers spares the neuraxium and blocks the nerves as they course within that tissue plane. Reasons for the growing popularity of CWFPB include (1) ease of performance; (2) excellent safety profile; (3) good efficacy in various clinical settings. The scope of this review is to address the use of RA in CS, with particular reference to the indications, techniques, and complications of currently available CWFPB (see Table A1, Appendix A).

\section{Techniques}

RA of the chest wall may be performed at various points along an arch coursing anteriorly from the posterior midline. With TEA as gold standard regarding the breadth of somatic and sympathetic blockade, CWFPB exhibit a variable decrement in their effect as they approach the anterior midline. Autonomic effects are retained proportionally to the extent of LA spread into the epidural space, and the area of sensory loss is inversely related to the distance between the injection spot and spine. A considerable inter-individual variation in the extent and intensity of CWFPB exists, and several reasons may represent the root cause of this: (1) existence of differential sensory blockade [13]; (2) reliance on passive LA spread to achieve analgesia; (3) redundant innervation between peripheral nerve territories, including midline overlapping [14,15].

\subsection{Thoracic Epidural Anaesthesia (TEA)}

The role of TEA in cardiac ERAS programs remains an intensely debated topic. TEA produces robust chest wall pain relief, yet it repeatedly failed to improve perioperative morbidity and mortality in CS populations [16]. Potential reasons include the fact that TEA benefits may have a disproportionate impact on CS pain or because TEA side effects and complications may offset its benefits. Notably, pain associated with CS is typically moderate [6], so less intense analgesia (i.e., CWFPB) might suffice. In contrast, adverse events associated with TEA may be clinically relevant (e.g., respiratory depression with epidural opioids and hypotension with epidural LA) and potentially catastrophic (e.g., SEH).

Cardiac sympatholysis was shown to benefit myocardial blood flow [17] but also blunt the heart capacity to cope with hemodynamic challenges, especially within specific subgroups such as those with established pulmonary hypertension [18].

The calculated maximum risks of SEH in CS after TEA were 1:1500 with 95\% confidence and 1:1000 with 99\% confidence, respectively [19]. In a recent meta-analysis of over 6000 patients, Landoni et al. estimated this risk at 1:3552 (95\% CI 1:2552-1:5841) [20]. Placing the epidural one day before surgery could prevent bleeding complications, but such practice patterns would contradict the very essence of ERAS programs.

Overall, minimization of risks outweighs maximization of analgetic potential. Adequate patient selection, risk factors, and anesthesiologist's expertise must be carefully balanced before pursuing TEA or any other type of neuraxial technique. Until more evidence becomes available, the risk-benefit ratio of neuraxial analgesia remains prohibitive. 


\subsection{Paravertebral Blocks (PVB)}

\subsubsection{Mechanism and Clinical Applications}

PVB involves LA injection into the thoracic paravertebral space (TPVS) to block the spinal nerve roots as they emerge from the intervertebral foramina. TPVS is a triangularshaped space on both sides of the vertebrae bounded anterolaterally by the parietal pleura, medially by the posterolateral parts of the vertebral body and posteriorly by the superior costotransverse ligament (SCTL) (see also Figure 1). TPVS communicates laterally with the intercostal space, and medially with the epidural space. TPVS is also contiguous with its contralateral counterpart but to a much lesser extent whereas its cranial extension remains ill-defined. Caudal and rostral segmental spread of the LA drug from the injection site generates multilevel ipsilateral somatic and autonomic blockade, with epidural and intercostal LA dispersions likely contributing substantially to analgesia [21]. The clinical effect of single-level $\mathrm{PVB}_{\mathrm{LM}}$ is highly variable because the LA spread is unpredictable [22]. Consequently, a multiple-injection technique was commonly considered superior to single-injection patterns $[23,24]$. This theory was first challenged by Renes et al. [25] and Marhofer et al. [26] who used US-guidance to perform PVB (PVB $\mathrm{BS}_{\text {) }}$. Later, Uppal et al. [27] demonstrated that single- and multilevel PVB $\mathrm{BS}_{\text {are equivalent }}$ regarding coverage and pain relief duration. Conveniently, the single-level $\mathrm{PVB}_{\mathrm{US}}$ are markedly faster and better tolerated by patients, two prerequisites of any ERAS strategy.

Compared to $\mathrm{PVB}_{\mathrm{LM}}, \mathrm{PVB}_{\mathrm{US}}$ are more reliable and safer [28]. Two assets, equivalent analgesia to TEA but with fewer complications [29-34] and unilateral sympathectomy, favored the resurgence of $\mathrm{PVB}_{\mathrm{US}}$. Still, the latter proves itself ineffectual in CS with sternotomy since this surgery requires bilateral nerve blockade.

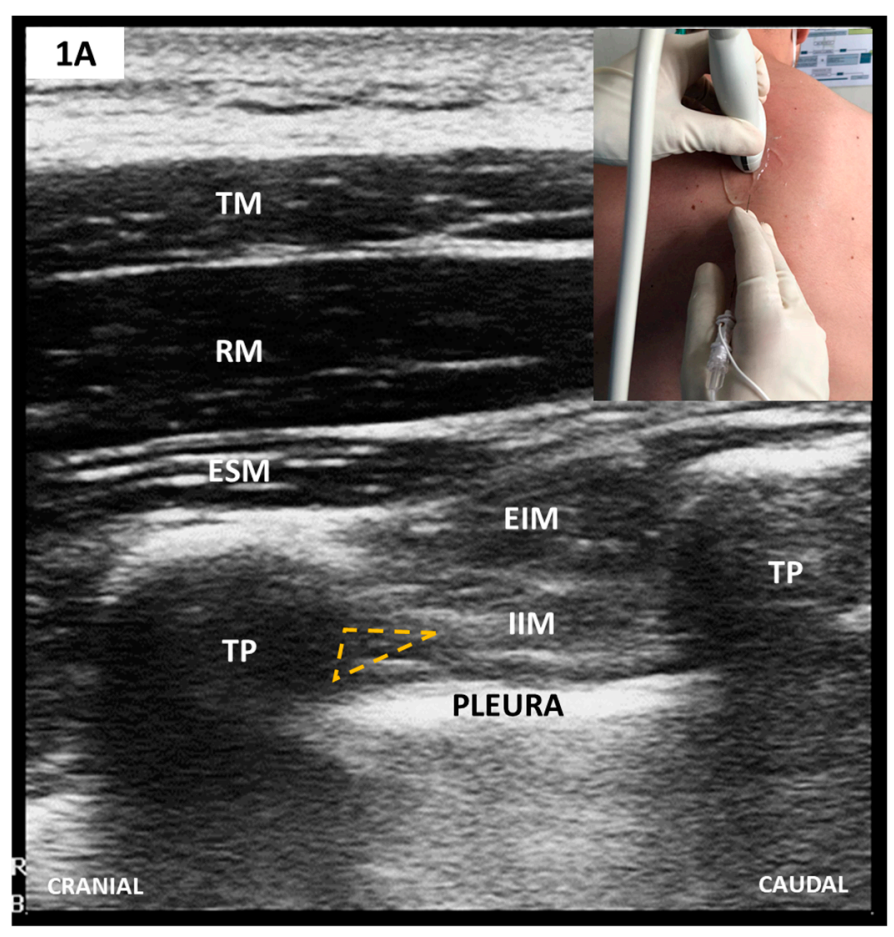

Figure 1. Cont. 


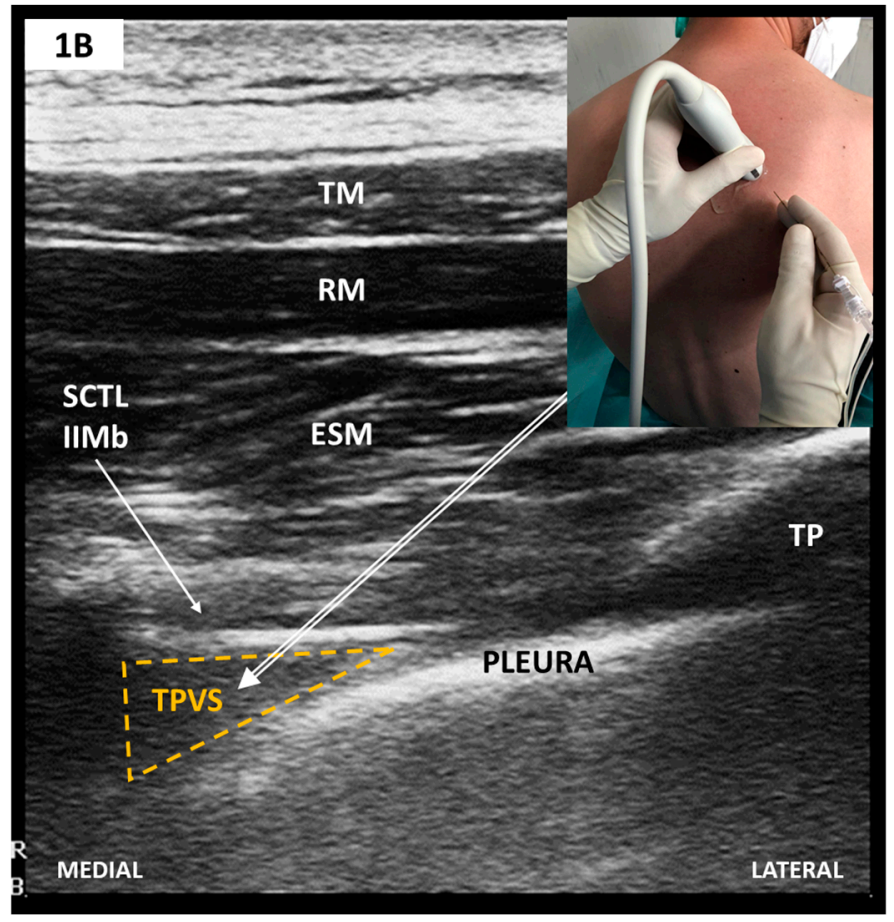

Figure 1. (A) Parasagittal scan of thoracic paravertebral space (TPVS); (B) Transverse/oblique scan of TPVS after 75-degree anti-clockwise rotation from A. The needle tip's target is TPVS, which, after probe rotation, appears enlarged and lies anteriorly to superior costotransverse ligament (SCTL)/IIMb (see text).TM, trapezius muscle; RM, rhomboid muscle; ESM, erector spinae muscle; EIM, external intercostal muscle; IIM, internal intercostal muscle; TP, transverse vertebral process; SCTL, superior costotransverse ligament; IIMb, internal intercostal membrane; TPVS, thoracic paravertebral space.

As with TEA, hemorrhagic complications represent a crucial factor to consider. In contrast to TEA, risk quantification of SEH after PVB is less evident and intensely debated. The latest American Society of Regional Anesthesia and Pain Medicine (ASRA) Practice Advisory on RA and anticoagulation maintains the same recommendations for PVB as for any other neuraxial block [11]. Equivocally, ASRA does not differentiate between $\mathrm{PVB}_{\mathrm{LM}}$ and $\mathrm{PVB}_{\mathrm{US}}$, and between single-shot PVB and PVB with catheters. New data suggests that US guidance during paravertebral blockade could virtually abrogate spinal injury risk even with the large heparin dosing needed in cardiopulmonary bypass (CPB) [35]. El Shora et al. recently compared $\mathrm{PVB}_{\mathrm{US}}$ with catheter to TEA to manage pain after on-pump CS [36]. Catheters were placed immediately after induction in both study groups, and LA infusion was started only postoperatively. $\mathrm{PVB}_{\mathrm{US}}$ were non-inferior to TEA regarding pain relief, and bleeding complications were not reported in either group.

Future studies will have to address two aspects to maximize the benefits and minimize the potential risks associated with $\mathrm{PVB}_{\mathrm{US}}$. The first is concerned with single-shot PVB being safer than PVB with TPVS catheters because catheter misplacement, including epidurally, is still possible even with US [37,38]. The second aspect is concerned with nerve blockade timing, as suggested by Richardson et al. [39]. Compared to $\mathrm{PVB}_{\mathrm{US}}$ established after surgery, preemptive $\mathrm{PVB}_{\mathrm{US}}$ may be better tailored to fast-tracking as it would also mitigate the intraoperative opioid consumption.

The best strategy to implement $\mathrm{PVB}_{\mathrm{US}}$ has yet to be established. Further research is needed before the routine use of paravertebral blockade in CS is either supported or refuted.

Sonoanatomy and Block Techniques (Figure 1)

$\mathrm{PVB}_{\mathrm{US}}$ have superseded $\mathrm{PVB}_{\mathrm{LM}}$ in every aspect. A comprehensive review described at least nine approaches, all of which share the same three sonoanatomical landmarks circumscribing TPVS—rib, pleura, and transverse process (TP) [40]. At present, formal 
recommendations on the best way to perform PVB $\mathrm{PSS}_{\mathrm{S}}$ do not exist. Instead, personal factors relating to skill, experience and perceived safety seem to play a decisive role. An objective comparative evaluation of currently used PVB $\mathrm{US}$ techniques is essential to enable an informed PVB-based MA.

TPVS scanning breaks down to 4 elements: (1) plane of US beam orientation (i.e., transversal versus sagittal); (2) needling technique (i.e., out-of-plane versus in-plane); (3) direction of angulation (i.e., lateral versus medial, and caudal versus cranial respectively) and (4) safety limit for needle tip (i.e., anteriorly or posteriorly to SCTL) [40]. Choosing between these elements entails a trade-off between two goals, simplicity and accuracy. The latter is advocated in our institute, so we perform an in-plane, lateral to medial, transversal/oblique approach with a safety limit set anteriorly to SCTL (see Figure 1). Based on currently available evidence, catheters are excluded with CPB heparin dosing.

Scanning starts with the linear-array transducer placed in a parasagittal plane to identify the adjacent TP, recognizable as flat, rectangular hypoechoic structures (see also Figure 2). Anti-clockwise rotation to a transversal/oblique plane displays the TPVS. The needle is inserted in-plane, latero-medially and advanced until it reaches the wedgedshaped TPVS. Adequate LA injection pushes the parietal pleura anteriorly. Preemptive bilateral single-shot blocks are performed at the level of the fourth thoracic vertebrae. This alone may provide intraoperative analgesia long enough to sustain most types of CS.

\subsection{Chest Wall Fascial Plane Blocks (CWFPB)}

2.3.1. Posterior CWFPB-Erector Spinae Plane Block (ESPB) and other PVB Variants Mechanism and Clinical Applications

Post-mortem data challenge the traditional view that TPVS is a discrete anatomical space and suggest that the SCTL is permeable to LA drugs [41]. Hence, paravertebral blockade of nerves could still be elicited by placing the needle tip outside but close enough to the TPVS.

US guidance has facilitated the emergence of several more superficial needle placement techniques, all collectively labelled as "paraspinal blocks" [42] or "PVB by proxy" [43]. These include the retrolaminar block (RLB) $[44,45]$, midpoint transverse process to pleura block (MTPB) [41], intercostal/paraspinal block (ICPB) [46], rhomboid intercostal and subserratus block (RISS) [47], and erector spinae plane block (ESPB) [48]. Depending on their underlying pathway of LA spread, these novel blocks produce a variable combination of ipsilateral somatic and autonomic blockades, the extent of which remains open for further research. Amongst them, ESPB is the most well characterized to date.

The ESPB target for LA deposition is the plane between the erector spinae muscle (ESM) and the thoracic TP tip. Correct single-level LA injection should lift the ESM off the TP and allow the ipsilateral craniocaudal volume-dependent [49] LA spread across several contiguous dermatomes (i.e., 3 to 7 intercostal spaces) [50]. As with PVB, transforaminal, intercostal and circumferential epidural diffusions likely contribute to its mechanism of action [50,51].

Krishna et al. compared bilateral single-shot ESPB with control (i.e., general anesthesia alone) in CS with sternotomy and found reduced postoperative pain, time to extubation, time to ambulation, opioid usage and total length of intensive care unit (ICU) stay [52]. Interestingly, rescue analgesia was reported in the intervention group only ten hours after extubation compared to six hours in the control group $(p=0.0001)$. Macaire et al. used a before-and-after design to show that in open CS a preemptive strategy with bilateral ESPB catheters is associated with reduced intra- and postoperative opioid consumption. Consequently, several ERAS endpoints were favorably altered, including postoperative adverse events (hypotension, nausea/vomiting and hyperglycemia) and times to chest tube removal and first mobilization. The authors found no differences in extubation time and pain during the first mobilization. Another RCT showed comparable postoperative pain scores between bilateral continuous ESPB and TEA in 50 patients undergoing open CS [53]. Finally, Bousquet at al. endorse the association of bilateral parasternal block 
with bilateral ESPB [54] given that ESPB alone may sometimes fail to provide adequate parasternal analgesia [55]. This dual blockade significantly reduced the intraoperative sufentanil and postoperative morphine usage in a 20-patient cohort [54]. These four studies did not report any RA related adverse effects, but then again, neither was appropriately powered to detect them.
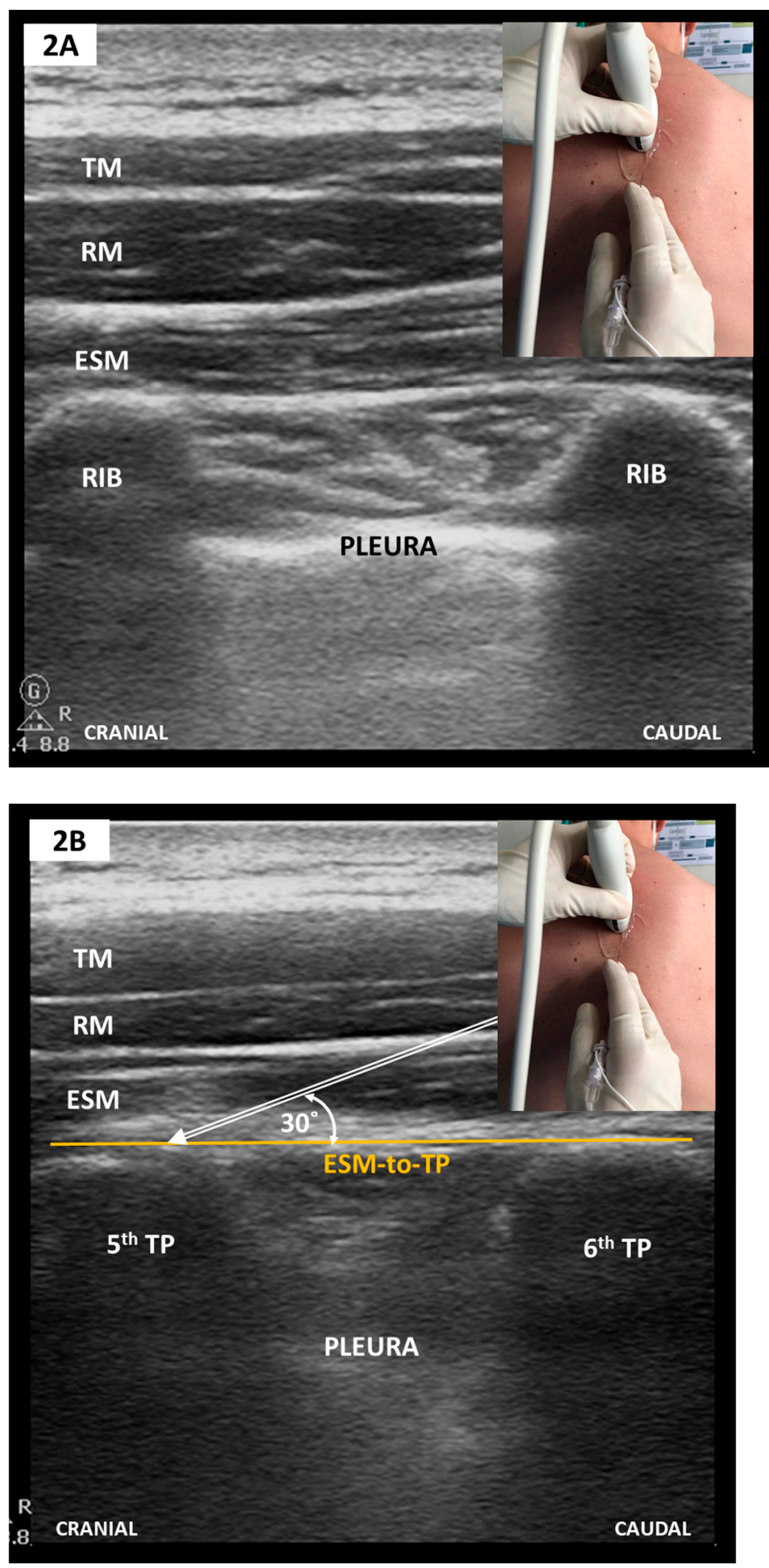

Figure 2. (A) Parasagittal scan—rib level; (B) Parasagittal scan—TP level (see text). TM, trapezius muscle; RM, rhomboid muscle; ESM, erector spinae muscle; TP, transverse vertebral process; ESM-to$\mathrm{TP}$, erector spinae muscle -to-transversus process plane. 
Although promising, results from these clinical studies are not generalizable. There is a potential bias concerning the small patient populations, blinding and randomization. Further studies are mandated to fully understand the benefits and extent of incorporating ESPB into routine clinical practice.

\section{Sonoanatomy and Block Tachnique (Figure 2)}

Scanning starts with the linear-array transducer set 5-6 cm away from the dorsal midline in a parasagittal orientation. The ribs are then displayed as rounded acoustic shadows with an interceding hyperechoic pleural line (see Figure 2A). Sliding the transducer medially along the short axis allows visualization of the TP as flat, squared-off acoustic shadows (see Figure 2B). Additionally, the pleural line is more in-depth and ill-defined. A too medial position identifies the thoracic laminae as a continuous flat hyperechoic line with regularly interspersed notches representing the facet joint interfaces. Needle insertion follows an in-plane approach, either craniocaudal or vice versa, to contact the ESM-to-TP plane. Real-time imaging guarantees correct LA hydro-dissection beneath the ESM and catheter placement whenever continuous pain relief is warranted. Single-level injection ESPBs (i.e., at the 5th thoracic vertebrae), as initially described by Forero et al. [48], continue to be the norm but this view has recently been challenged by Tulgar et al. who propose a bilevel approach to ensure a more homogeneous LA spread [56].

\subsubsection{Anterolateral CWFPB-Pectoral Blocks and Serratus Plane Block Mechanism and Clinical Application}

Anterolateral CWFPB provide ipsilateral somatic anesthesia of the upper anterolateral hemithorax but may spare the anterior branches of the intercostal nerves and hence do not consistently provide anesthetic coverage to the ipsilateral parasternal region [12]. This theoretically hinders their use in CS with sternotomy. Established techniques include the serratus anterior plane block (SAPB) [57] and the pectoralis block type I (PECS I) [58] and II (PECS II) [59]. Whilst PECS I and SAPB are distinct blocks, targeting two separate musculofascial planes, PECS II merely represents an attempt to achieve both PECS I and SAPB during a two-staged single needle pass (see also Figure 3).

A 40-patient RCT compared PECS II with no block as part of a postoperative MA strategy in patients undergoing CS with sternotomy. PECS group patients were extubated earlier, had lower pain scores and fewer episodes of rescue analgesia [60].

SAPB was studied in minimally invasive heart valve surgery (MIHVS) with right thoracotomy and minimally invasive direct coronary artery bypass (MIDCAB) with left thoracotomy. Berthoud et al. compared postoperative single-shot deep SAPB to continuous wound infiltration (CWI) and reported significantly lower morphine consumption, reduced length of ICU stay and improved pain control during the first $48 \mathrm{~h}$ following MIHVS [61]. Another group of authors compared pre-incisional single-shot and postoperative catheterbased deep SABP against parenteral morphine [62]. The intraoperative opioid usage remained unaffected, but the combined regional nerve blockade significantly spared the postoperative morphine consumption. Nevertheless, this did not change the postoperative course, that is, ICU and hospital lengths of stay and ventilator-free days. According to one study, SAPB appears well suited for MIDCAB thoracotomies [63] but remains inferior to PVB in terms of analgesic coverage and intensity [64]. Lastly, SAPB and PECS II showed an equivalent analgesic effect in an RCT conducted on pediatric patients undergoing CS with thoracotomy without $\mathrm{CPB}$ [65].

Anterolateral CWFPB have an excellent safety profile that will allow their ongoing integration in cardiac ERAS pathways. Their impact relies markedly on adequate timing (i.e., pre- versus postoperative blockade) and indication. 

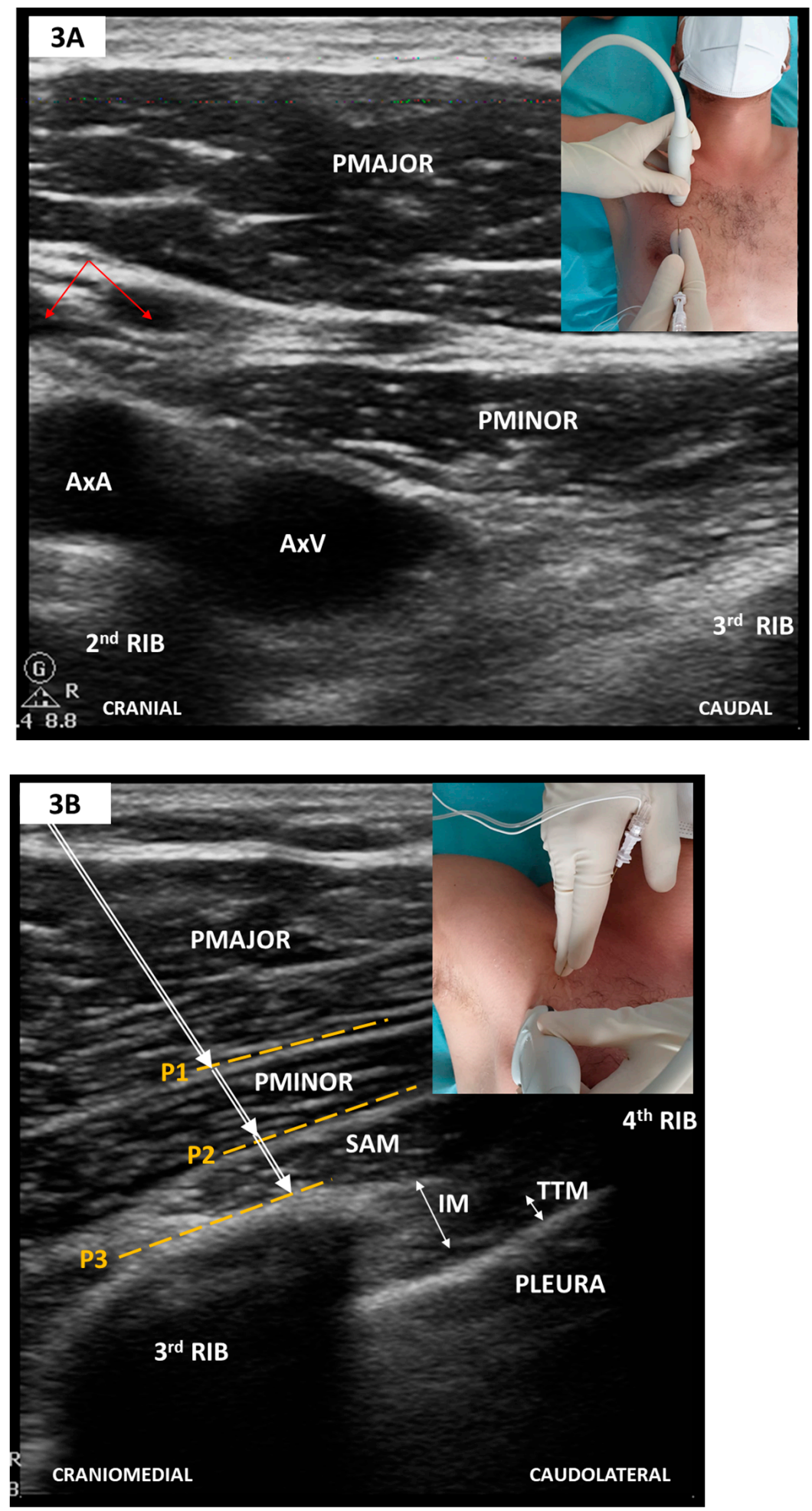

Figure 3. (A) Parasagittal scan along the medioclavicular line-2nd rib level; (B) Oblique scan after a slight medial tilt with inferolateral sliding towards the midaxillary line-4th rib level (see text). PMAJOR, pectoralis major muscle; PMINOR, pectoralis minor muscle; AxA, axillary artery; AxV, axillary vein; red arrows, thoracoacromial artery and vein; SAM, serratus anterior muscle; IM, intercostal muscle; TTM, transversus thoracic muscle; P1, PECS I plane; P2, superficial plane for SAPB/PECS II; P3, deep plane for SAPB/PECS II. To elicit an adequate SAPB coverage, P2 or P3 need to be targeted at the 4 th or 5 th rib level. 
Sonoanatomy and Block Technique (Figure 3)

PECS I targets the lateral (C5-C7) and medial (C8-T1) pectoral nerves travelling within the fascial plane between the pectoralis minor and major muscles. SAPB targets the plane either above or below the serratus anterior muscle (SAM). Although some authors favor the latter [66], the differences between these two juxtaposed fascial planes have not yet been elucidated. SAPB blocks the lateral cutaneous branches of the intercostal branches and, when superficially performed, the long thoracic (C5-C7) and thoracodorsal nerves (C6-C8). A single needle pass may secure both blocks (i.e., PECS II) and achieve ipsilateral anesthesia of the anterolateral hemithorax and axilla. Scanning is carried out craniocaudally along the midclavicular line, sliding laterally to intersect the midaxillary line at the fourth and fifth ribs level. Needle insertion follows an in-plane, mediolateral approach (see Figure 3).

\subsubsection{Anteromedial CWFPB-Parasternal Block Variants}

Mechanism and Clinical Applications

These blocks complement the anterolateral CWFPB by providing anesthesia confined to the parasternal region [67]. Depending on where the anterior branches of the intercostal nerves are blocked, anteromedial CWFPB consist of two interrelated approaches: the pecto-intercostal fascial plane block (PIFB) [68] and transverse thoracic muscle plane block (TTMPB) [69]. The former is the injection of LA between the external intercostal and pectoralis major muscles. The latter targets a deeper fascial layer between the inner intercostal and transverse thoracic muscles. Some authors promote PIFB because of a potentially superior safety profile $[70,71]$ and others inform that the transverse thoracic muscles may be too thin to identify with US [72].

Both parasternal variants have been evaluated in CS with sternotomy. Two small RCTs looked at bilateral single-shot PIFB as part of a postoperative MA regimen. Adverse effects were not recorded, and pain scores were significantly reduced in both trials [73,74]. There was a trend towards reduced cumulative opioid consumption, but this reached statistical significance in only one trial [73]. Anecdotal evidence supports the combination of PIFB with other fascial plane blocks as clinically required [75]. Furthermore, such an approach may be readily generalizable to all CWFPB and lend itself to an individualized USRA.

Preemptive single-shot bilateral TTMPB was compared with placebo in an RCT of 48 adult patients undergoing CS with median sternotomy. Several ERAS-specific outcomes were significantly improved, including first $24 \mathrm{~h}$ opioid requirement, rescue analgesia, pain scores, and ICU discharge time [76]. Similar findings have been reported by several pediatric RCTs in CS via midline sternotomy $[77,78]$, with one trial using a combination of TTMPB with rectus sheath block [79].

Sonoanatomy and Block Technique (Figure 4)

The linear-array probe is placed in the parasagittal plane, $1 \mathrm{~cm}$ lateral from sternum's edge in the fourth or fifth intercostal space (see Figure 4). Structures to be identified include the pectoralis major muscle, intercostal muscle, thoracic transversus muscles and rib shadows with the intervening pleural line. The internal thoracic artery and vein run longitudinally and share the same plane with TTMPB (i.e., superficial to the thoracic transversus muscle). Perforating branches may cross the intercostal muscles to reach the sternum. Careful scanning in two orthogonal planes is thus mandated before needle insertion to avoid inadvertent vascular puncture. To this end, some authors recommend a transversal approach with lateral to medial needle advancement [72]. Regardless of probe orientation, one or both target planes can then be selected to deposit LA using an in-plane approach. 

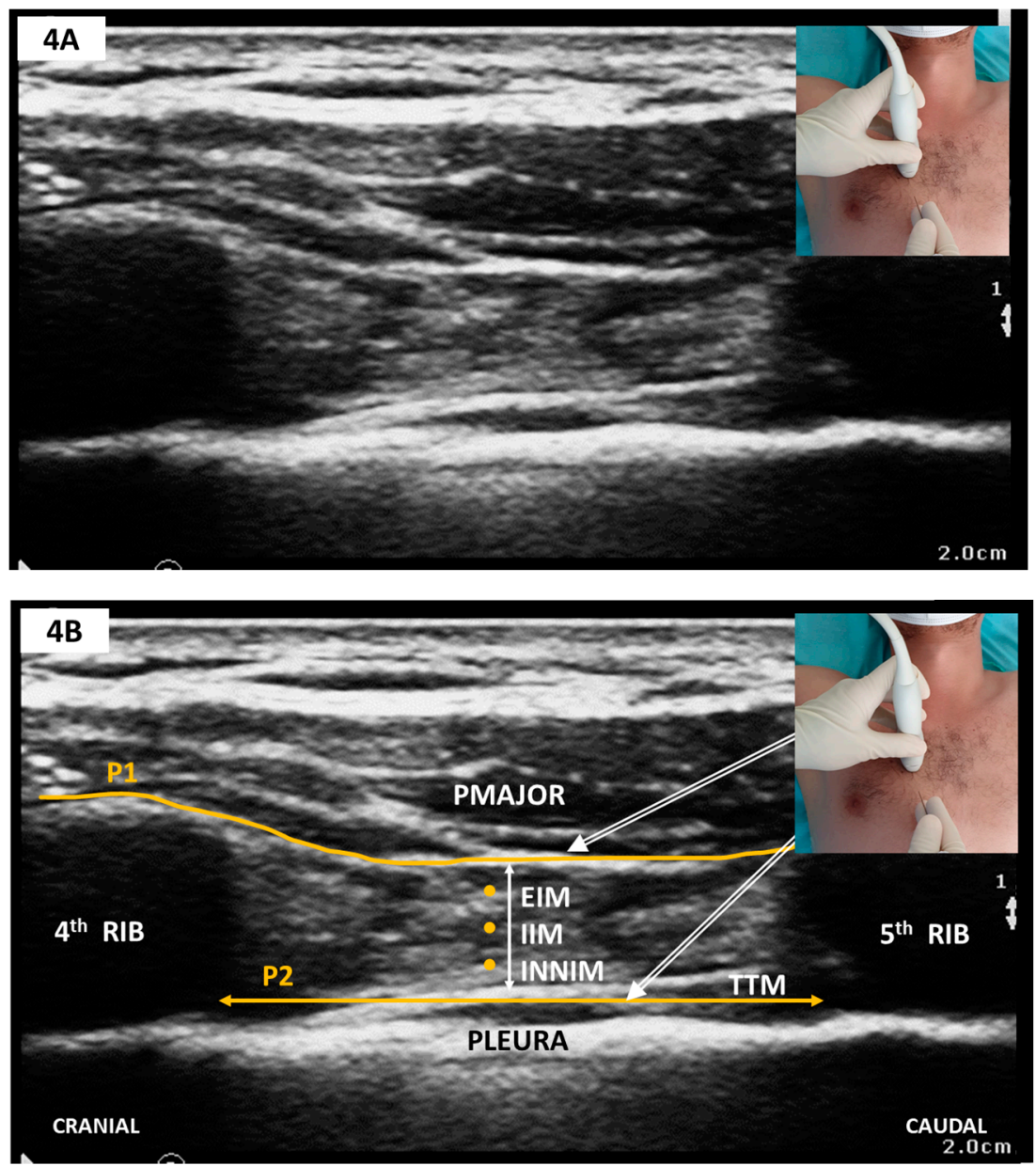

Figure 4. (A) Sagittal parasternal scan; (B) Sagittal parasternal scan with markings. Note that TTM appears as a hypoechoic band folding over the hyperechoic pleura. PMAJOR, pectoralis major muscle; EIM, external intercostal muscle; IIM, internal intercostal muscle; INNIM, innermost intercostal muscle; TTM, thoracic transversus muscle; P1, target plane for PIFB; P2, target plane for TTMPB.

\section{Complications}

US-assistance has dramatically increased the safety and efficiency of RA techniques resulting in improved outcomes. Reports of complications are scarce and unsystematic. Although local anesthetic systemic toxicity (LAST) is virtually a shared complication of all blocks, it may be more often reported with blocks performed in highly vascular compartments. That was the case with PVB in a case series of eight patients undergoing coronary artery bypass grafting $(\mathrm{CABG})$, where potentially toxic ropivacaine concentrations were reportedly common [80]. Of note, PVB were performed using a landmark technique, and catheters were placed in all patients. Similarly, Lockwood et al. cautioned that systemic absorption after $\mathrm{PVB}_{\mathrm{LM}}$ is highly probable, especially with continuous catheter infusions [81]. Such findings are compelling enough to consider, regardless of block location and technique, the following precautions: (1) do not exceed the maximum recommended LA dose (see also Table A1); (2) addition of epinephrine to delay systemic absorption; (3) be ready to monitor, recognize and treat LAST; and (4) consider US to enable precise needle advancement [82].

Sympathectomy varies in extent and intensity and is common with posterior nerve blocks, mostly bilateral PVB. Compared to PVB, posterior CWFPB seem less associated with hypotension and bradycardia [83], probably because the epidural spread is lower than initially thought [84]. 
Performance of PVB and CWFPB can, in theory, result in iatrogenic pneumothorax. Nevertheless, the incidence of this will remain undefined given that chest tubes are invariably present in CS with median sternotomy.

Although PVB are formally contraindicated with CPB anticoagulation regimens, the same recommendations may not apply to the more superficial CWFPB. To date, there are no reported hemorrhagic complications after any of the CWFPB, with anecdotal evidence supporting their use in contexts otherwise prohibitive for classical neuraxial techniques [85].

\section{Perspective}

The best way to provide RA as part of cardiac ERAS strategies has become a topic of considerable interest. Future trials are needed to compare currently available USRA techniques (e.g., PVB versus posterior and anterior CWFPB), establish the optimum time to start the nervous blockade (i.e., pre- versus postoperatively) and understand the role of various perineural adjuvants. This last issue could have momentous consequences as it may enable prolonged duration of single-injection nerve blocks and circumvent the use of catheters [86]. Catheter-free RA is faster to implement, more tolerable and perceivably safer. Furthermore, a simplified technique without additional catheter attempts may promote adherence and widespread use amongst anesthesiologists.

Monitoring regional blockade can be difficult under general anesthesia. With conscious, awake patients, preemptive blockades could be assessed by sensory testing (i.e., pinprick or cold stimulus), but this would delay the operation by at least twenty minutes. Intraoperative nociception monitors could help run an individualized and precise opioid-sparing strategy starting with induction. One trial is currently underway to evaluate the efficacy of ESPB on perioperative opioid consumption in CS with sternotomy during goal-directed anti-nociception using the Nociception Level (NOL) index (NCT04338984).

\section{Conclusions}

USRA favors improved outcomes coupled with an excellent safety profile and has gained considerable momentum in fast-track cardiac surgery over the last decade. Young adults (i.e., mean age 50 years) undergoing elective cardiac surgeries with relatively short aortic cross clamp times seem to derive the greatest benefits, including opioid sparing, reduced time to extubation, earlier mobilization and improved perioperative pain control. Upcoming trials are expected to provide the missing links needed to standardize the integration of RA in cardiac ERAS pathways. Until such time, USRA remains a valuable adjunct in cardiac perioperative care that calls for a personalized application encompassing both anesthesiologist's expertise and patient's characteristics.

Author Contributions: C.B. wrote the concept and first draft. All other authors reviewed and edited the manuscript. All authors have read and agreed to the published version of the manuscript.

Funding: This research received no external funding.

Institutional Review Board Statement: Not applicable.

Informed Consent Statement: Not applicable.

Data Availability Statement: Not applicable.

Acknowledgments: The authors would like to thank Adrian Wong, Department of Intensive Care Medicine and Anesthesia, King's College Hospital, Denmark Hill, London, UK for constructive criticism of the manuscript.

Conflicts of Interest: The authors declare no conflict of interest. 


\section{Appendix A}

Table A1. Ultrasound-guided regional nerve blocks in cardiac surgery-technical considerations.

\begin{tabular}{|c|c|c|c|c|c|c|c|}
\hline Block & Target Plane or Space & Target Nerve & Autonomic Blockade & $\begin{array}{l}\text { Maximum Area of } \\
\text { Sensory Loss }\end{array}$ & $\begin{array}{c}\text { Surgical } \\
\text { Approach-Best Fit }\end{array}$ & $\begin{array}{c}\text { LA Volume for } \\
\text { Single-Shot Block/Side \# }\end{array}$ & Practice Patterns \\
\hline PVB & TPVS & $\begin{array}{l}\text { Dorsal and ventral rami of } \\
\text { spinal nerve roots }\end{array}$ & Yes & Ipsilateral hemithorax & Sternotomy (BLB) & $\begin{array}{l}20-25 \mathrm{~mL} \text { if single-level (4th } \\
\text { TP) or } 4-5 \mathrm{~mL} \text { with } \\
\text { multilevel strategy }\end{array}$ & $\begin{array}{l}\text { - Formal contraindication } \\
\text { with anticoagulation }\end{array}$ \\
\hline \multirow[t]{2}{*}{ ESP } & \multirow[t]{2}{*}{ ESM-to-TP } & \multirow[t]{2}{*}{$\begin{array}{l}\text { Dorsal and ventral rami of } \\
\text { spinal nerve roots }\end{array}$} & \multirow[t]{2}{*}{ Yes } & \multirow[t]{2}{*}{ Ipsilateral hemithorax } & \multirow[t]{2}{*}{ Sternotomy (BLB) } & \multirow[t]{2}{*}{$20 \mathrm{~mL}$ at the 5th TP } & $\begin{array}{l}\text { - Bilevel-injection to } \\
\text { improve LA spread }\end{array}$ \\
\hline & & & & & & & - Preemptive approach \\
\hline PECS I & PMAJOR-to-PMINOR & $\begin{array}{l}\text { Medial and lateral } \\
\text { pectoral nerves }\end{array}$ & No & $\begin{array}{l}\text { Narrow upper } \\
\text { anterolateral chest wall }\end{array}$ & $\begin{array}{l}\text { Minimally invasive } \\
\text { thoracotomy (ULB) }\end{array}$ & $15 \mathrm{~mL}$ at the $3 \mathrm{rd}$ rib & $\begin{array}{l}\text { - Inadequate for } \\
\text { sternotomy }\end{array}$ \\
\hline \multirow{2}{*}{ PECS II } & \multirow{2}{*}{$\begin{array}{l}\text { PMAJOR-to-PMINOR } \\
\text { (1) and SUPRA- or } \\
\text { SUB-SAM (2) }\end{array}$} & \multirow{2}{*}{ PECS I, LTN and TDN } & \multirow{2}{*}{ No } & \multirow{2}{*}{$\begin{array}{c}\text { Wide upper } \\
\text { anterolateral chest wall, } \\
\text { including axilla }\end{array}$} & \multirow{2}{*}{$\begin{array}{l}\text { Minimally invasive } \\
\text { thoracotomy (ULB) }\end{array}$} & \multirow{2}{*}{$30 \mathrm{~mL}$ at the $3 \mathrm{rd}$ rib } & $\begin{array}{l}\text { - Inadequate for } \\
\text { sternotomy }\end{array}$ \\
\hline & & & & & & & $\begin{array}{l}\text { - Perform (1) after (2) with } \\
\text { a single-pass approach }\end{array}$ \\
\hline \multirow[b]{2}{*}{ SAPB } & \multirow[b]{2}{*}{ SUPRA- or SUB-SAM } & \multirow{2}{*}{$\begin{array}{l}\text { Lateral branches of ICN, } \\
\text { including LTN and TDN } \\
\text { with superficial SABP }\end{array}$} & \multirow[b]{2}{*}{ No } & \multirow[b]{2}{*}{ Lateral chest wall } & \multirow{2}{*}{$\begin{array}{l}\text { Minimally invasive } \\
\text { thoracotomy (ULB) }\end{array}$} & \multirow[b]{2}{*}{$30-40 \mathrm{~mL}$ at the 4 th -5 th rib } & $\begin{array}{l}\text { - Inadequate for } \\
\text { sternotomy }\end{array}$ \\
\hline & & & & & & & $\begin{array}{l}\text { - Anterior spread with } \\
\text { deep SAPB; posterior spread } \\
\text { with superficial SAPB }\end{array}$ \\
\hline PIFB & PMAJOR-to-EIM & Anterior branches of ICN & No & Parasternal & Sternotomy (BLB) & $20 \mathrm{~mL}$ at the 4 th rib & - Combined \\
\hline TTMPB & INNIM-to-TTM & Anterior branches of ICN & No & Parasternal & Sternotomy (BLB) & $20 \mathrm{~mL}$ at the 4 th rib & - Combined \\
\hline
\end{tabular}



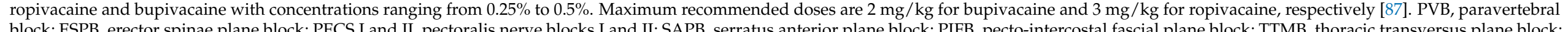

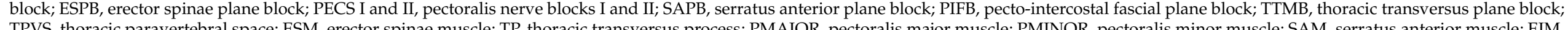

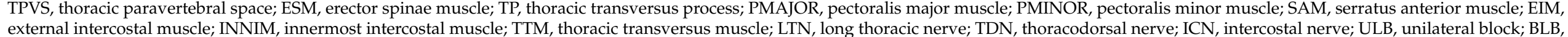
bilateral block. 


\section{References}

1. Roques, F.; Nashef, S.A.M.; Michel, P.; Gauducheau, E.; De Vincentiis, C.; Baudet, E.; Cortina, J.; David, M.; Faichney, A.; Gavrielle, F.; et al. Risk factors and outcome in European cardiac surgery: Analysis of the EuroSCORE multinational database of 19030 patients. Eur. J. Cardio-Thoracic. Surg. 1999, 15, 816-823. [CrossRef]

2. Wahba, A.; Milojevic, M.; Boer, C.; De Somer, F.M.; Gudbjartsson, T.; van den Goor, J.; Jones, T.J.; Lomivorotov, V.; Merkle, F.; Ranucci, M.; et al. 2019 EACTS/EACTA/EBCP guidelines on cardiopulmonary bypass in adult cardiac surgery. Br. J. Anaesth. 2019, 123, 713-757. [CrossRef]

3. Ranucci, M. Anaesthesia and cardiopulmonary bypass aspects of fast track. Eur. Hear. J. Suppl. 2017, 19, A15-A17. [CrossRef]

4. Gerstein, N.S.; Petersen, T.R.; Ramakrishna, H. Evaluating the Cardiac Anesthesiologist's Role in Surgical Outcomes-A Reappraisal Based on Recent Evidence. J. Cardiothorac. Vasc. Anesth. 2017, 31, 283-290. [CrossRef]

5. $\quad$ Engelman, D.T.; Ali, W.B.; Williams, J.B.; Perrault, L.P.; Reddy, V.S.; Arora, R.C.; Roselli, E.E.; Khoynezhad, A.; Gerdisch, M.; Levy, J.H.; et al. Guidelines for Perioperative Care in Cardiac Surgery: Enhanced Recovery After Surgery Society Recommendations. JAMA Surg. 2019, 154, 755-766. [CrossRef]

6. Mueller, X.M.; Tinguely, F.; Tevaearai, H.T.; Revelly, J.P.; Chioléro, R.; von Segesser, L.K. Pain location, distribution, and intensity after cardiac surgery. Chest 2000, 118, 391-396. [CrossRef]

7. Lahtinen, P.; Kokki, H.; Hynynen, M. Pain after cardiac surgery: A prospective cohort study of 1-year incidence and intensity. Anesthesiology 2006, 105, 794-800. [CrossRef]

8. Ochroch, J.; Usman, A.; Kiefer, J.; Pulton, D.; Shah, R.; Grosh, T.; Patel, S.; Vernick, W.; Gutsche, J.T.; Raiten, J. Reducing Opioid Use in Patients Undergoing Cardiac Surgery-Preoperative, Intraoperative, and Critical Care Strategies. J. Cardiothorac. Vasc. Anesth. 2020. [CrossRef]

9. Shanthanna, H.; Ladha, K.S.; Kehlet, H.; Joshi, G.P. Perioperative Opioid Administration: A Critical Review of Opioid-free versus Opioid-sparing Approaches. Anesthesiology 2020. [CrossRef]

10. Mittnacht, A.J.; Shariat, A.; Weiner, M.M.; Malhotra, A.; Miller, M.A.; Mahajan, A.; Bhatt, H.V. Regional Techniques for Cardiac and Cardiac-Related Procedures. J. Cardiothorac. Vasc. Anesth. 2019, 33, 532-546. [CrossRef] [PubMed]

11. Horlocker, T.T.; Vandermeuelen, E.; Kopp, S.L.; Gogarten, W.; Leffert, L.R.; Benzon, H.T. Regional Anesthesia in the Patient Receiving Antithrombotic or Thrombolytic Therapy: American Society of Regional Anesthesia and Pain Medicine Evidence-Based Guidelines (Fourth Edition). Reg. Anesth. Pain Med. 2018, 43, 263-309. Available online: http://rapm.bmj.com/content/43/3/2 63.abstract (accessed on 20 January 2021). [CrossRef]

12. Kelava, M.; Alfirevic, A.; Bustamante, S.; Hargrave, J.; Marciniak, D. Regional Anesthesia in Cardiac Surgery: An Overview of Fascial Plane Chest Wall Blocks. Anesth Analg 2020, 131, 127-135. Available online: https:/ /journals.lww.com/anesthesia-analgesia/ Fulltext/2020/07000/Regional_Anesthesia_in_Cardiac_Surgery_An.23.aspx (accessed on 20 January 2021). [CrossRef]

13. Raymond, S.A.; Gissen, A.J. Mechanisms of Differential Nerve Block BT. In Local Anesthetics; Strichartz, G.R., Ed.; Springer: Berlin/Heidelberg, Germany, 1987; pp. 95-164. [CrossRef]

14. Capek, S.; Tubbs, R.S.; Spinner, R.J. Do cutaneous nerves cross the midline? Clin. Anat. 2015, 28, 96-100. [CrossRef]

15. Ladak, A.; Tubbs, R.S.; Spinner, R.J. Mapping sensory nerve communications between peripheral nerve territories. Clin. Anat. 2014, 27, 681-690. [CrossRef]

16. Guay, J.; Kopp, S. Epidural analgesia for adults undergoing cardiac surgery with or without cardiopulmonary bypass. Cochrane Database Syst. Rev. 2019, 3, CD006715. [CrossRef]

17. Bulte, C.S.; Boer, C.; Hartemink, K.J.; Kamp, O.; Heymans, M.W.; Loer, S.A.; de Marchi, S.F.; Vogel, R.; Bouwman, R.A. Myocardial Microvascular Responsiveness During Acute Cardiac Sympathectomy Induced by Thoracic Epidural Anesthesia. J. Cardiothorac. Vasc. Anesth. 2017, 31, 134-141. [CrossRef] [PubMed]

18. Wink, J.; Veering, B.T.; Aarts, L.P.H.J.; Wouters, P.F. Effects of Thoracic Epidural Anesthesia on Neuronal Cardiac Regulation and Cardiac Function. Anesthesiology 2019, 130, 472-491. [CrossRef]

19. Ho, A.M.; Chung, D.C.; Joynt, G.M. Neuraxial blockade and hematoma in cardiac surgery: Estimating the risk of a rare adverse event that has not (yet) occurred. Chest 2000, 117, 551-555. [CrossRef]

20. Landoni, G.; Isella, F.; Greco, M.; Zangrillo, A.; Royse, C.F. Benefits and risks of epidural analgesia in cardiac surgery. BJA Br. J. Anaesth. 2015, 115, 25-32. [CrossRef]

21. Karmakar, M.K. Thoracic Paravertebral Block. Anesthesiology 2001, 95, 771-780. [CrossRef]

22. Cowie, B.; McGlade, D.; Ivanusic, J.; Barrington, M.J. Ultrasound-guided thoracic paravertebral blockade: A cadaveric study. Anesth. Analg. 2010, 110, 1735-1739. [CrossRef] [PubMed]

23. Naja, Z.M.; El-Rajab, M.; Al-Tannir, M.A.; Ziade, F.M.; Tayara, K.; Younes, F.; Lönnqvist, P.A. Thoracic paravertebral block: Influence of the number of injections. Reg. Anesth. Pain Med. 2006, 31, 196-201. [CrossRef]

24. Kotzé, A.; Scally, A.; Howell, S. Efficacy and safety of different techniques of paravertebral block for analgesia after thoracotomy: A systematic review and metaregression. Br. J. Anaesth. 2009, 103, 626-636. [CrossRef]

25. Renes, S.H.; Bruhn, J.; Gielen, M.J.; Scheffer, G.J.; van Geffen, G.J. In-plane ultrasound-guided thoracic paravertebral block: A preliminary report of 36 cases with radiologic confirmation of catheter position. Reg. Anesth. Pain Med. 2010, 35, 212-216. [CrossRef] 
26. Marhofer, D.; Marhofer, P.; Kettner, S.C.; Fleischmann, E.; Prayer, D.; Schernthaner, M.; Lackner, E.; Willschke, H.; Schwetz, P.; Zeitlinger, M. Magnetic resonance imaging analysis of the spread of local anesthetic solution after ultrasound-guided lateral thoracic paravertebral blockade: A volunteer study. Anesthesiology 2013, 118, 1106-1112. [CrossRef] [PubMed]

27. Uppal, V.; Sondekoppam, R.V.; Sodhi, P.; Johnston, D.; Ganapathy, S. Single-Injection Versus Multiple-Injection Technique of Ultrasound-Guided Paravertebral Blocks: A Randomized Controlled Study Comparing Dermatomal Spread. Reg. Anesth. Pain Med. 2017, 42, 575-581. [CrossRef]

28. Vogt, A. Review about ultrasounds in paravertebral blocks. Eur. J. Pain Suppl. 2011, 5, 489-494. Available online: http: / / www.sciencedirect.com/science/article/pii/S1754320711000460 (accessed on 24 January 2021). [CrossRef]

29. D'Ercole, F.; Arora, H.; Kumar, P.A. Paravertebral Block for Thoracic Surgery. J. Cardiothorac. Vasc. Anesth. 2018, 32, 915-927. [CrossRef]

30. Baidya, D.K.; Khanna, P.; Maitra, S. Analgesic efficacy and safety of thoracic paravertebral and epidural analgesia for thoracic surgery: A systematic review and meta-analysis. Interact. Cardiovasc. Thorac. Surg. 2014, 18, 626-635. [CrossRef] [PubMed]

31. Yeung, J.H.Y.; Gates, S.; Naidu, B.V.; Wilson, M.J.A.; Gao Smith, F. Paravertebral block versus thoracic epidural for patients undergoing thoracotomy. Cochrane Database Syst. Rev. 2016, 2, CD009121. [CrossRef]

32. Scarci, M.; Joshi, A.; Attia, R. In patients undergoing thoracic surgery is paravertebral block as effective as epidural analgesia for pain management? Interact. Cardiovasc. Thorac. Surg. 2010, 10, 92-96. [CrossRef] [PubMed]

33. Davies, R.G.; Myles, P.S.; Graham, J.M. A comparison of the analgesic efficacy and side-effects of paravertebral vs epidural blockade for thoracotomy-A systematic review and meta-analysis of randomized trials. Br. J. Anaesth. 2006, 96, 418-426. [CrossRef]

34. Scarfe, A.J.; Schuhmann-Hingel, S.; Duncan, J.K.; Ma, N.; Atukorale, Y.N.; Cameron, A.L. Continuous paravertebral block for post-cardiothoracic surgery analgesia: A systematic review and meta-analysis. Eur. J. Cardio-Thoracic. Surg. Off. J. Eur. Assoc. Cardio-Thoracic. Surg. 2016, 50, 1010-1018. [CrossRef] [PubMed]

35. Okitsu, K.; Iritakenishi, T.; Iwasaki, M.; Imada, T.; Fujino, Y. Risk of Hematoma in Patients With a Bleeding Risk Undergoing Cardiovascular Surgery With a Paravertebral Catheter. J. Cardiothorac. Vasc. Anesth. 2017, 31, 453-457. [CrossRef]

36. El Shora, H.A.; El Beleehy, A.A.; Abdelwahab, A.A.; Ali, G.A.; Omran, T.E.; Hassan, E.A.; Arafat, A.A. Bilateral Paravertebral Block versus Thoracic Epidural Analgesia for Pain Control Post-Cardiac Surgery: A Randomized Controlled Trial. Thorac. Cardiovasc. Surg. 2020, 68, 410-416. [CrossRef]

37. Luyet, C.; Herrmann, G.; Ross, S.; Vogt, A.; Greif, R.; Moriggl, B.; Eichenberger, U. Ultrasound-guided thoracic paravertebral puncture and placement of catheters in human cadavers: Where do catheters go? Br. J. Anaesth. 2011, 106, 246-254. [CrossRef]

38. Luyet, C.; Eichenberger, U.; Greif, R.; Vogt, A.; Szücs Farkas, Z.; Moriggl, B. Ultrasound-guided paravertebral puncture and placement of catheters in human cadavers: An imaging study. Br. J. Anaesth. 2009, 102, 534-539. [CrossRef] [PubMed]

39. Richardson, J.; Sabanathan, S.; Jones, J.; Shah, R.D.; Cheema, S.; Mearns, A.J. A prospective, randomized comparison of preoperative and continuous balanced epidural or paravertebral bupivacaine on post-thoracotomy pain, pulmonary function and stress responses. Br. J. Anaesth. 1999, 83, 387-392. [CrossRef] [PubMed]

40. Krediet, A.C.; Moayeri, N.; van Geffen, G.J.; Bruhn, J.; Renes, S.; Bigeleisen, P.E.; Groen, G.J. Different Approaches to Ultrasoundguided Thoracic Paravertebral Block: An Illustrated Review. Anesthesiology 2015, 123, 459-474. [CrossRef] [PubMed]

41. Costache, I.; De Neumann, L.; Ramnanan, C.J.; Goodwin, S.L.; Pawa, A.; Abdallah, F.W.; McCartney, C.J.L. The mid-point transverse process to pleura (MTP) block: A new end-point for thoracic paravertebral block. Anaesthesia 2017, 72, 1230-1236. [CrossRef] [PubMed]

42. Wild, K.; Chin, K.J. Regional Techniques for Thoracic Wall Surgery. Curr. Anesthesiol. Rep. 2017, 7, 212-219. [CrossRef]

43. Costache, I.; Pawa, A.; Abdallah, F.W. Paravertebral by proxy-Time to redefine the paravertebral block. Anaesthesia 2018, 73, 1185-1188. [CrossRef]

44. Voscopoulos, C.; Palaniappan, D.; Zeballos, J.; Ko, H.; Janfaza, D.; Vlassakov, K. The ultrasound-guided retrolaminar block. Can. J. Anaesth. 2013, 60, 888-895. [CrossRef]

45. Murouchi, T.; Yamakage, M. Retrolaminar block: Analgesic efficacy and safety evaluation. J. Anesth. 2016, 30, 1003-1007. [CrossRef]

46. Roué, C.; Wallaert, M.; Kacha, M.; Havet, E. Intercostal/paraspinal nerve block for thoracic surgery. Anaesthesia 2016, 71, 112-113. [CrossRef]

47. Elsharkawy, H.; Maniker, R.; Bolash, R.; Kalasbail, P.; Drake, R.L.; Elkassabany, N. Rhomboid Intercostal and Subserratus Plane Block: A Cadaveric and Clinical Evaluation. Reg. Anesth. Pain Med. 2018, 43, 745-751. [CrossRef]

48. Forero, M.; Adhikary, S.D.; Lopez, H.; Tsui, C.; Chin, K.J. The Erector Spinae Plane Block: A Novel Analgesic Technique in Thoracic Neuropathic Pain. Reg. Anesth. Pain Med. 2016, 41, 621-627. [CrossRef] [PubMed]

49. Choi, Y.J.; Kwon, H.J.; O, J.; Cho, T.H.; Won, J.Y.; Yang, H.M.; Kim, S.H. Influence of injectate volume on paravertebral spread in erector spinae plane block: An endoscopic and anatomical evaluation. PLoS ONE 2019, 14, e0224487. Available online: https: / / pubmed.ncbi.nlm.nih.gov /31658293 (accessed on 4 February 2021). [CrossRef] [PubMed]

50. Vidal, E.; Giménez, H.; Forero, M.; Fajardo, M. Erector spinae plane block: A cadaver study to determine its mechanism of action. Rev. Esp. Anestesiol. Reanim. 2018, 65, 514-519. [CrossRef]

51. Schwartzmann, A.; Peng, P.; Maciel, M.A.; Forero, M. Mechanism of the erector spinae plane block: Insights from a magnetic resonance imaging study. Can. J. Anaesth. 2018, 65, 1165-1166. [CrossRef] 
52. Krishna, S.N.; Chauhan, S.; Bhoi, D.; Kaushal, B.; Hasija, S.; Sangdup, T.; Bisoi, A.K. Bilateral Erector Spinae Plane Block for Acute Post-Surgical Pain in Adult Cardiac Surgical Patients: A Randomized Controlled Trial. J. Cardiothorac. Vasc. Anesth. 2019, 33, 368-375. [CrossRef]

53. Nagaraja, P.S.; Ragavendran, S.; Singh, N.G.; Asai, O.; Bhavya, G.; Manjunath, N.; Rajesh, K. Comparison of continuous thoracic epidural analgesia with bilateral erector spinae plane block for perioperative pain management in cardiac surgery. Ann. Card. Anaesth. 2018, 21, 323-327.

54. Bousquet, P.; Labaste, F.; Gobin, J.; Marcheix, B.; Minville, V. Bilateral Parasternal Block and Bilateral Erector Spinae Plane Block Reduce Opioid Consumption in During Cardiac Surgery. J. Cardiothorac. Vasc. Anesth. 2021. [CrossRef]

55. Taketa, Y.; Irisawa, Y.; Fujitani, T. Ultrasound-guided erector spinae plane block elicits sensory loss around the lateral, but not the parasternal, portion of the thorax. J. Clin. Anesth. 2018, 47, 84-85. [CrossRef] [PubMed]

56. Tulgar, S.; Selvi, O.; Ozer, Z. Clinical experience of ultrasound-guided single and bi-level erector spinae plane block for postoperative analgesia in patients undergoing thoracotomy. J. Clin. Anesth. 2018, 50, 22-23. [CrossRef] [PubMed]

57. Blanco, R.; Parras, T.; McDonnell, J.G.; Prats-Galino, A. Serratus plane block: A novel ultrasound-guided thoracic wall nerve block. Anaesthesia 2013, 68, 1107-1113. [CrossRef] [PubMed]

58. Blanco, R. The "pecs block": A novel technique for providing analgesia after breast surgery. Anaesthesia 2011, 66, 847-848. [CrossRef]

59. Blanco, R.; Fajardo, M.; Parras Maldonado, T. Ultrasound description of Pecs II (modified Pecs I): A novel approach to breast surgery. Rev. Esp. Anestesiol. Reanim. 2012, 59, 470-475. [CrossRef]

60. Kumar, K.N.; Kalyane, R.N.; Singh, N.G.; Nagaraja, P.S.; Krishna, M.; Babu, B.; Varadaraju, R.; Sathish, N.; Manjunatha, N. Efficacy of bilateral pectoralis nerve block for ultrafast tracking and postoperative pain management in cardiac surgery. Ann. Card. Anaesth. 2018, 21, 333-338.

61. Berthoud, V.; Ellouze, O.; Nguyen, M.; Konstantinou, M.; Aho, S.; Malapert, G.; Girard, C.; Guinot, P.G.; Bouchot, O.; Bouhemad, B. Serratus anterior plane block for minimal invasive heart surgery. BMC Anesthesiol. 2018, 18, 144. [CrossRef]

62. Toscano, A.; Capuano, P.; Costamagna, A.; Burzio, C.; Ellena, M.; Scala, V.; Pasero, D.; Rinaldi, M.; Brazzi, L. The Serratus Anterior Plane Study: Continuous Deep Serratus Anterior Plane Block for Mitral Valve Surgery Performed in Right Minithoracotomy. J. Cardiothorac. Vasc. Anesth. 2020, 34, 2975-2982. [CrossRef] [PubMed]

63. Gautam, S.; Pande, S.; Agarwal, A.; Agarwal, S.K.; Rastogi, A.; Shamshery, C.; Singh, A. Evaluation of Serratus Anterior Plane Block for Pain Relief in Patients Undergoing MIDCAB Surgery. Innovations 2020, 15, 148-154. [CrossRef]

64. Moll, V.; Maffeo, C.; Mitchell, M.; Ward, C.T.; Groff, R.F.; Lee, S.C.; Halkos, M.E.; Jabaley, C.S.; O'Reilly-Shah, V.N. Association of Serratus Anterior Plane Block for Minimally Invasive Direct Coronary Artery Bypass Surgery With Higher Opioid Consumption: A Retrospective Observational Study. J. Cardiothorac. Vasc. Anesth. 2018, 32, 2570-2577. [CrossRef]

65. Kaushal, B.; Chauhan, S.; Saini, K.; Bhoi, D.; Bisoi, A.K.; Sangdup, T.; Khan, M.A. Comparison of the Efficacy of UltrasoundGuided Serratus Anterior Plane Block, Pectoral Nerves II Block, and Intercostal Nerve Block for the Management of Postoperative Thoracotomy Pain After Pediatric Cardiac Surgery. J. Cardiothorac. Vasc. Anesth. 2019, 33, 418-425. [CrossRef]

66. Pérez, M.F.; Duany, O.; de la Torre, P.A. Redefining PECS Blocks for Postmastectomy Analgesia. Reg. Anesth. Pain Med. 2015, 40, 729-730. [CrossRef] [PubMed]

67. Ueshima, H.; Otake, H. Addition of transversus thoracic muscle plane block to pectoral nerves block provides more effective perioperative pain relief than pectoral nerves block alone for breast cancer surgery. BJA Br. J. Anaesth. 2017, 118, 439-443. [CrossRef]

68. De la Torre, P.A.; García, P.D.; Alvarez, S.L.; Miguel, F.J.G.; Pérez, M.F. A novel ultrasound-guided block: A promising alternative for breast analgesia. Aesthetic. Surg. J. 2014, 34, 198-200. [CrossRef]

69. Ueshima, H.; Kitamura, A. Blocking of Multiple Anterior Branches of Intercostal Nerves (Th2-6) Using a Transversus Thoracic Muscle Plane Block. Reg. Anesth. Pain Med. 2015, 40, 388. [CrossRef] [PubMed]

70. Scimia, P.; Fusco, P.; Tedesco, M.; Sepolvere, G. Bilateral ultrasound-guided parasternal block for postoperative analgesia in cardiac surgery: Could it be the safest strategy? Reg. Anesth. Pain Med. 2020. Available online: http://rapm.bmj.com/content/ early /2020/01/19/rapm-2019-100872.abstract (accessed on 20 January 2021). [CrossRef]

71. Del Buono, R.; Costa, F.; Agrò, F.E. Parasternal, Pecto-intercostal, Pecs, and Transverse Thoracic Muscle Plane Blocks: A Rose by Any Other Name Would Smell as Sweet. Reg. Anesth. Pain Med. 2016, 41, 791-792. Available online: http://rapm.bmj.com/ content/41/6/791.abstract (accessed on 1 November 2020). [CrossRef]

72. Murata, H.; Hida, K.; Hara, T. Transverse Thoracic Muscle Plane Block: Tricks and Tips to Accomplish the Block. Reg. Anesth. Pain Med. 2016, 41, 411-412. Available online: http:/ /rapm.bmj.com/content/41/3/411.2.abstract (accessed on 1 November 2020). [CrossRef] [PubMed]

73. Kumar, A.K.; Chauhan, S.; Bhoi, D.; Kaushal, B. Pectointercostal Fascial Block (PIFB) as a Novel Technique for Postoperative Pain Management in Patients Undergoing Cardiac Surgery. J. Cardiothorac. Vasc. Anesth. 2021, 35, 116-122. [CrossRef] [PubMed]

74. Khera, T.; Murugappan, K.R.; Leibowitz, A.; Bareli, N.; Shankar, P.; Gilleland, S.; Wilson, K.; Oren-Grinberg, A.; Novack, V.; Venkatachalam, S.; et al. Ultrasound-Guided Pecto-Intercostal Fascial Block for Postoperative Pain Management in Cardiac Surgery: A Prospective, Randomized, Placebo-Controlled Trial. J. Cardiothorac. Vasc. Anesth. 2021, 35, 896-903. [CrossRef]

75. Jones, J.; Murin, P.J.; Tsui, J.H. Combined Pectoral-Intercostal Fascial Plane and Rectus Sheath Blocks for Opioid-Sparing Pain Control After Extended Sternotomy for Traumatic Nail Gun Injury. J. Cardiothorac. Vasc. Anesth. 2021. [CrossRef] 
76. Aydin, M.E.; Ahiskalioglu, A.; Ates, I.; Tor, I.H.; Borulu, F.; Erguney, O.D.; Celik, M.; Dogan, N. Efficacy of UltrasoundGuided Transversus Thoracic Muscle Plane Block on Postoperative Opioid Consumption After Cardiac Surgery: A Prospective, Randomized, Double-Blind Study. J. Cardiothorac. Vasc. Anesth. 2020, 34, 2996-3003. [CrossRef] [PubMed]

77. Abdelbaser, I.I.; Mageed, N.A. Analgesic efficacy of ultrasound guided bilateral transversus thoracis muscle plane block in pediatric cardiac surgery: A randomized, double-blind, controlled study. J. Clin. Anesth. 2020, 67, 110002. [CrossRef]

78. Zhang, Y.; Chen, S.; Gong, H.; Zhan, B. Efficacy of Bilateral Transversus Thoracis Muscle Plane Block in Pediatric Patients Undergoing Open Cardiac Surgery. J. Cardiothorac. Vasc. Anesth. 2020, 34, 2430-2434. [CrossRef] [PubMed]

79. Yamamoto, T.; Seino, Y.; Matsuda, K.; Imai, H.; Bamba, K.; Sugimoto, A.; Shiraishi, S.; Schindler, E. Preoperative Implementation of Transverse Thoracic Muscle Plane Block and Rectus Sheath Block Combination for Pediatric Cardiac Surgery. J. cardioThorac. Vasc. Anesth. 2020, 34, 3367-3372. Available online: https://www.sciencedirect.com/science/article/pii/S1053077020307126 (accessed on 1 November 2020). [CrossRef]

80. Ho, A.H.; Karmakar, M.K.; Ng, S.K.; Wan, S.; Ng, C.S.H.; Wong, R.H.L.; Chan, S.K.C.; Joynt, G.M. Local anaesthetic toxicity after bilateral thoracic paravertebral block in patients undergoing coronary artery bypass surgery. Anaesth. Intensive Care 2016, 44, 615-619. [CrossRef]

81. Lockwood, G.G.; Cabreros, L.; Banach, D.; Punjabi, P.P. Continuous bilateral thoracic paravertebral blockade for analgesia after cardiac surgery: A randomised, controlled trial. Perfusion 2017, 32, 591-597. [CrossRef]

82. Chin, K.J. Thoracic wall blocks: From paravertebral to retrolaminar to serratus to erector spinae and back again-A review of evidence. Best Pract. Res. Clin. Anaesthesiol. 2019, 33, 67-77. [CrossRef] [PubMed]

83. Fang, B.; Wang, Z.; Huang, X. Ultrasound-guided preoperative single-dose erector spinae plane block provides comparable analgesia to thoracic paravertebral block following thoracotomy: A single center randomized controlled double-blind study. Ann. Transl. Med. 2019, 7, 174. [CrossRef]

84. Chin, K.J.; El-Boghdadly, K. Mechanisms of action of the erector spinae plane (ESP) block: A narrative review. Can. J. Anesth. Can. D'anesthésie 2021. [CrossRef] [PubMed]

85. De Cassai, A.; Ieppariello, G.; Ori, C. Erector spinae plane block and dual antiplatelet therapy. Minerva. Anestesiol. 2018, 84, 1230-1231. [CrossRef]

86. Gao, Z.; Xiao, Y.; Wang, Q.; Li, Y. Comparison of dexmedetomidine and dexamethasone as adjuvant for ropivacaine in ultrasoundguided erector spinae plane block for video-assisted thoracoscopic lobectomy surgery: A randomized, double-blind, placebocontrolled trial. Ann. Transl. Med. 2019, 7, 668. [CrossRef] [PubMed]

87. Josh Luftig, P.A.; Mantuani, D.; Herring, A.A.; Dixon, B.; Clattenburg, E.; Nagdev, A. The authors reply to the optimal dose and volume of local anesthetic for erector spinae plane blockade for posterior rib fractures. Am. J. Emerg. Med. 2018, 36, 1103-1104. [CrossRef] 